\title{
LA DIPLOMACIA ROMANA EN LA MONARQUÍA: UNA ESCUELA PARA LA DIPLOMACIA MODERNA*
}

\author{
ROMAN DIPLOMACY DURING THE MONARCHY: \\ A SCHOOL FOR MODERN DIPLOMACY
}

\section{RAÚl BUONO-CORE V.**}

\section{RESUMEN}

Este artículo tiene como principal objetivo destacar cómo en el período de la monarquía romana ya se pueden ver importantes iniciativas de parte de los reyes, con el fin de mantener buenas relaciones con sus vecinos. Los mecanismos empleados, como las embajadas, los acuerdos y tratados, todos ellos amparados y avalados por el derecho y los dioses, nos permiten distinguir ya fórmulas de carácter diplomático, que se convertirán en las bases de la convivencia de Roma con otros pueblos y culturas, como también, en un sistema para las relaciones exteriores que, en muchos de sus aspectos, los encontramos en la diplomacia actual.

Palabras clave: Diplomacia, fides, fetiales, foedus, ius gentium.

\section{ABSTRACT}

The main objective of this article is to highlight that during the Roman Monarchy the kings had already introduced major initiatives in order to maintain good relations with their neighbors. The mechanisms used, such as embassies, agreements and treaties, all protected and guaranteed by the law and the gods, allow us to distinguish diplomatic formulas that will become the foundations of the coexistence of Rome with other peo-

* Este artículo forma parte del Proyecto de Investigación Fondecyt No 1120487 titulado: "Diplomacia y Autorrepresentación en la Roma Republicana".

** Doctor en Historia por la Universidad de Pisa (Italia). Profesor Titular de Historia Antigua en el Instituto de Historia de la Pontificia Universidad Católica de Valparaíso, y profesor de Historia Antigua del Departamento de Historia de la Universidad de Chile. Correo electrónico: rbuonocu@ucv.cl 
ples and cultures, as well as a system for foreign relations that, in many ways, can be found in current diplomacy.

Keywords: Diplomacy, fides, fetiales, foedus, ius gentium.

Recibido: 21.10.13. Aceptado: 06.12.13.

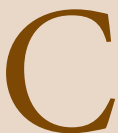

UANDO ALUDIMOS a la diplomacia o a las relaciones diplomáticas debemos entender que nos referimos al establecimiento de relaciones formales entre dos entidades políticamente independientes que puedan demostrar el dominio de un territorio, la posesión de un ejército o algo similar que cumpla de alguna manera esas funciones, además de una organización política que dé garantías a la contraparte. Durante el periodo de la monarquía las aldeas y las pequeñas comunidades latinas, por las condiciones imperantes, no se podían dar el lujo de desarrollar una amplia política exterior, pero aun así, a pesar de los escasos datos que nos entregan las fuentes, debemos deducir que las relaciones de este tipo indudablemente existieron (Poucet, 1985; Grandazzi, 1991; Carandini, 1997).

Desde los primeros tiempos, los representantes de la política exterior romana, haciendo uso de sus cualidades oratorias, eran los encargados de llevar un mensaje esencialmente oral, aun cuando sabemos de la existencia de una escritura aproximadamente desde el siglo VIII a.C. ${ }^{1}$. Esta probablemente se usaba con mayor frecuencia en el mundo de la religión y en la redacción de los textos que estipulaban las condiciones de los tratados (foedus) en este período de la historia de Roma. Dionisio de Halicarnaso recuerda que en el templo de Dio Fidio hay un tratado que Tarquinio establece con el pueblo latino de los Gabinos, al que los romanos llaman Sanco; se trataba de un escudo de madera recubierto con la piel del buey sacrificado para esa ocasión con la finalidad de ratificar los tratados, que llevaba inscrito en antiguos caracteres los términos de estos acuerdos ${ }^{2}$. Al establecerse en estos tratados condiciones por escrito, es un dato que nos permite comprobar la existencia de un sistema diplomático de carácter más o menos formal. Sabemos que el término foedus, alianza o tratado, es una palabra muy antigua, de raíz indoeuropea. Por lo tanto, no es un anacronismo que Tito Livio la use desde el primer capítulo de su Historia, porque estaba vigente en el siglo I a.C. El historiador señala que se hizo una alianza entre Eneas y los latinos. El verbo que usa tiene el significado original de

\footnotetext{
${ }^{1}$ Cicerón $(1924,2,10)$.

${ }^{2}$ Dionisio de Halicarnaso (1984-1988, IV, 58, 4).
} 
herir. Esta relación entre realizar un tratado y la herida ha sido entendida como referencia a la antigua manera de hacer las alianzas: mezclando la sangre de los aliados. Esto nos lleva a formas de un ritual primitivo, que nos comprueba la antigüedad del término. Hay un elemento religioso operando al mismo tiempo que se opera un tratado, porque lo que se quiere a través del foedus es la unión de los dos grupos.

No obstante hay otros problemas, por ejemplo, la diferente denominación de los vecinos de Roma en fuentes como Plutarco, Tito Livio y Dionisio de Halicarnaso, denominación que es imprecisa y dispar. Cuando se refieren a los latinos que habitan en los alrededores, se refieren a vicinas gentes; en cambio a los que habitan en los bordes del territorio se les denomina omnium circa finitimorum, y a los latinos más tradicionales y antiguos los llaman prisci latini ${ }^{3}$. Vemos, por ejemplo, que cuando Tarquinio recibe a los legados de todas las ciudades se debe entender que son los representantes de los latinos, de la nación latina ${ }^{4}$. Hay diferencias en los datos que nos entregan las fuentes, porque para Dionisio de Halicarnaso son legados, en cambio para Tito Livio es un acto de sometimiento o de sumisión de los latinos $^{5}$. En este caso nos encontramos ante el problema de que no existe un término preciso para referirse a la Liga Latina, quedando el asunto en la ambigüedad. Por más que hasta ahora se haya intentado aclarar esto, la realidad es que por el momento es muy difícil identificar con precisión las relaciones entre romanos y latinos. Hay quienes piensan que los prisci latini corresponderían a los ciudadanos de Alba y sus colonias, las que habrían constituido la primitiva Liga latina, a pesar de que los datos que entregan las fuentes son poco prolijos en ese sentido (Liou-Gille, 1997). Al momento de entrar en deducciones, no hay que olvidar que este es un período que se debe analizar con la mayor cautela, sobre todo cuando se trata de sus instituciones políticas. La utilización ideológica que hacen los romanos del período republicano y del Imperio de las leyendas relacionadas con Rómulo no

\footnotetext{
${ }^{3}$ Tito Livio (1994-1997, 1, 9, 2): “Entonces, por consejo del Senado, Rómulo envió una legación a los pueblos circundantes a presentar una petición de alianza y de enlaces matrimoniales con el nuevo pueblo,..."; 1, 19, 4: “Lo cerró Numa, una vez llevada a cabo la unión con los pueblos vecinos con tratados de alianza, al quedar libres de preocupación por el peligro exterior"; 1, 32, 13: "Dado que los pueblos de los antiguos latinos o individuos antiguos latinos hicieron o cometieron delito contra el pueblo romano de los quirites; dado que el pueblo romano de los quirites decidió que hubiera guerra con los antiguos latinos, o que al Senado del pueblo romano de los quirites dio su parecer acuerdo y decisión de que se hiciese la guerra a los antiguos latinos, por ese motivo yo, al igual que el pueblo romano, declaro y hago la guerra a los pueblos de los antiguos latinos y a los ciudadanos antiguos latinos".

${ }^{4}$ Dionisio de Halicarnaso (1984-1988, 3, 54, 54); Tito Livio (1994-1997, 1, 38, 3-4-5).

${ }^{5}$ Dionisio de Halicarnaso(1984-1988, 3, 54, 1); Tito Livio (1994-1997, 1, 38, 4, 5).
} 
nos impide que se conviertan en una base indispensable para un adecuado conocimiento del período arcaico (Grandazzi, 1991, p. 83; Aulliard, 2006, p. 54). Los datos que tenemos a disposición en las fuentes seguramente no tuvieron como finalidad dejar solamente un testimonio de las actividades diplomáticas, por lo que debemos suponer que posiblemente hay un buen número de aspectos que no quedaron recogidos, porque no se consideraron o porque deliberadamente se ignoraron. A pesar de esto, me parece que las evidencias nos permiten hacer un análisis con cierta precisión, teniendo presente que el área geográfica en que la diplomacia romana se desarrollará durante la monarquía es un territorio reducido, y se limita prácticamente a los pueblos que habitan los territorio vecinos. Me refiero esencialmente a los latinos, sabinos y etruscos. En el caso de estos últimos, los datos son algo más exactos. Resultan también sorprendentes los tempranos contactos de Roma con Marsella ${ }^{6}$ y con los foceos ${ }^{7}$, como también la solicitud de asistencia religiosa que Tarquinio hace en el oráculo de Delfos ${ }^{8}$, para lo cual envía como legados a sus hijos Arrunte y Tito junto a Lucio Junio Bruto. A pesar de estos contactos fuera de Italia, no me parece posible considerar que la diplomacia romana de ese período tuvo una proyección desproporcionada e insospechada; si bien creció, no se puede olvidar el hecho de que en esos tiempos el peso político de Roma era débil, por lo tanto es prácticamente imposible pretender algún tipo de regulación para una forma de hacer política negociada. Si vemos una mayor intensidad en la actividad diplomática con los últimos reyes, no hay una diferencia sideral en la intensidad de esas relaciones en el período de Rómulo o Tulio Hostilio, o con el de Tarquinio el Soberbio a finales del siglo VI a.C. Se debe aceptar que este es un momento en el cual se están echando las bases de un sistema de relaciones exteriores que tendrá con el tiempo, un carácter internacional con representación universal. Es difícil sostener que durante la monarquía hubo una política exterior definida o permanente, primero porque la diplomacia fue de exclusiva responsabilidad de los reyes y porque, en realidad, con los datos a nuestra disposición, no se ve una continuidad en esas relaciones, sino que aparecen más bien como situaciones ocasionales que son resueltas a través de una acción diplomática que, por lo tanto, dependía exclusivamente de la voluntad del rey de turno. Rómulo, Tulio Hostilio y los dos Tarquinio parecen más activos que Numa, Anco Marcio y Servio Tulio.

${ }^{6}$ Justino, 45, 5, 3 .

${ }^{7}$ Justino, $43,3,4$.

${ }^{8}$ Dionisio de Halicarnaso (1984-1988, 4, 69, 2-4); Cicerón (1924, 2, 44); Tito Livio (19941997, 1, 56, 5-12). 
Rómulo es el responsable del inicio de la diplomacia romana por su rol de fundador y creador de las instituciones más antiguas de la ciudad (Alföldi, 1965, p. 249; Martin, 1982-1984, p. 233). La visión jurídica y religiosa de sus antepasados influyó también en el carácter jurídico y religioso de una diplomacia que estaba recién dando sus primeros pasos. ${ }^{9}$. El derecho y la fuerza son dos herramientas que Roma usará indistintamente al servicio de la diplomacia, argumento que quedará en evidencia desde los primeros tiempos, cuando se produce el conflicto con los sabinos, al que se pone fin con un tratado que une a los dos pueblos en una sola realidad ${ }^{10}$. Rómulo, desde los inicios, es el conductor de las operaciones militares y diplomáticas, convirtiendo la guerra en una herramienta política cuando no hay otra posibilidad. El monarca privilegia un entendimiento diplomático con sus vecinos, proponiendo alianzas a través de la vía de la negociación ${ }^{11}$. Es probable que estos primeros pasos de una diplomacia aún inexperta hayan hecho posible más adelante la creación de un lenguaje o vocabulario aplicado a esta. Las relaciones de orden diplomático establecidas por Rómulo rara vez se asocian con conflictos provocados. En las guerras o conquistas en perjuicio de los cenicenses, crustuminos y antemnates, como también de Medulia, Cameria o Fidenas, no hay ningún tipo de contactos diplomáticos (Aulliard, 2006, p. 59). La única excepción es el conflicto con Veyes que se constituye en el último conflicto militar del reinado de Rómulo, en el cual se hacen dos fallidos intentos de carácter diplomático ${ }^{12}$. Las operaciones militares estaban encadenadas entre sí, por lo que la diplomacia, con un escenario de esas características, tuvo escasas posibilidades de lograr algún éxito. Es muy probable que los mediocres resultados de los primeros intentos diplomáticos de Rómulo, junto a su natural agresividad, pueden haber influido en el menor uso que el rey hace de la diplomacia en los conflictos

${ }^{9}$ Tito Livio (1994-1997, 1, 8, 7; 1, 9, 1).

${ }^{10}$ Cicerón (1924, 2, 7); Tito Livio (1994-1997, 1, 13, 4-5): “El gesto emociona a soldados y jefes. Se hace un silencio y una quietud súbita; después los jefes se adelantan a estipular una alianza. No sólo establecen la paz, sino que integran los dos pueblos en uno solo. Forman un reino común, la base del poder para todos ellos la trasladan a Roma, que se vio así duplicada, y para hacer también alguna concesión a los sabinos tomaron todos el nombre de quirites por Cures. Como recuerdo de aquel combate, el lugar en que el caballo dejó en tierra firme a Curcio después de salir de la profunda marisma se llamó Lago Curcio".

${ }^{11}$ Tito Livio (1994-1997, 1, 9, 2):"Entonces, por consejo del Senado, Rómulo envió una legación a los pueblos circundantes a presentar una petición de alianza y de enlaces matrimoniales con el nuevo pueblo...".

${ }^{12}$ Para el primer contacto diplomático de Veyes con Rómulo (720 a.C. ca.): Plutarco (1985b, 25, 2-3) y Dionisio de Halicarnaso (1984-1988, 2, 54, 3); para el segundo contacto diplomático de Veyos con Rómulo (720 a.C. ca.): Tito Livio (1994-1997, 1, 15); Dionisio de Halicarnaso (19841988, 2, 55, 5-6) y Plutarco (1985b, 25, 5). 
que se sucederán más adelante. Aun cuando la información podría estar incompleta, Rómulo aparece involucrado en ocho contactos o acciones diplomáticas, de las cuales aparece enviando tres y recibiendo cinco. Con la excepción de los primeros contactos con los latinos, las relaciones diplomáticas durante el reinado de Rómulo están caracterizadas por su simplicidad, realidad que va de acuerdo con el carácter bastante rústico de las comunidades que en esos tiempos habitan en Roma y sus alrededores como los sabinos, latinos y las ciudades de Lavinium y Veyes. El caso de Lavinium es particularmente interesante, porque fue la única ciudad con la cual se llegó a concretar un foedus sostenible en el tiempo. En las fuentes esta relación aparece en dos momentos desiguales, primero al recibirse en Roma a los legados de Lavinium, estos son maltratados por parientes del rey Tito Tacio, lo que significa la violación del ius gentium que los amparaba. Este hecho no va a ser perdonado por Lavinium, por lo que, en ocasión de una visita de carácter religiosa de Tito Tacio a esa ciudad, va a ser asesinado, situación ante la cual Rómulo reaccionará prefiriendo la paz, la que quedará ratificada al renovarse la alianza entre las dos $\operatorname{ciudades}^{13}$. Según el relato de las fuentes, estas generalmente hacen aparecer a Roma defendiéndose de las agresiones de los pueblos vecinos ${ }^{14}$, de los ataques de los cenicenses, crustuminos y antemnates, después del rapto de las sabinas o del ataque de Veyes al territorio romano, saqueándolo.

Debido a la agresividad de Rómulo ningún conflicto necesita ser precedido de una declaración de guerra. Lleva a cabo siete guerras contra las ciudades de Caenina, Antemnes, Crustumeria, Fidenae, Veyes, Cameria y los Sabinos, y ninguna de estas guerras es declarada. Ahora bien, todos esos conflictos son anteriores a la instauración del rito fecial, que se convierte obligatoriamente en un vínculo entre fides, fetiales y foedus.

Sin embargo, la tradición parece cuidadosa de mostrar a un Rómulo respetuoso del bellum iustum, pero aún estamos muy lejos de la formaliza-

13 Tito Livio (1994-1997, 1, 14, 1-3): “Algunos años más tarde, unos parientes del rey Tacio maltratan a los legados de los laurentes; al invocar los laurentes el derecho de gentes, pesó más ante Tacio la influencia y los ruegos de los suyos y, como consecuencia, se hizo objeto del castigo, que ellos eran acreedores, pues una vez que asistió en Lavinio a un sacrificio solemne se produjo una revuelta y fue asesinado. Se dice que Rómulo reaccionó ante este hecho con menos pesar del que debía, bien porque no compartía el poder con mucho convencimiento, o bien por estimar que había sido muerto no sin razón. Descartó pues la guerra; pero para que hubiese una expiación de la ofensa a los legados y de la muerte del rey, la alianza entre Roma y Lavinio fue renovada".

Plutarco (1985b, 23, 1-3); Dionisio de Halicarnaso (1984-1988 2, 51-53).

14 Tito Livio (1994-1997, 1, 10, 3-11; 1, 15, 2-3); Plutarco (1985b, 24, 3-4). 
ción de ese concepto. A pesar de que el fundador sale siempre vencedor de estos enfrentamientos, por los testimonios a nuestra disposición sabemos que son guerras inevitables, provocadas por la agresividad de sus vecinos.

Numa Pompilio, el segundo rey de Roma, es sabino y se dice que era un gran conocedor del derecho humano y divino. No se lo elige, entonces, por sus condiciones militares; hay otra preocupación que anima a los romanos para elegir a su rey. Numa es lo contrario de Rómulo, aparece como el creador de una diplomacia protegida por los dioses. Las acciones diplomáticas del segundo rey de Roma se perfilan principalmente en la imagen de un soberano pacífico y piadoso, una imagen completamente diferente a la de Rómulo. Su estilo de gobierno se basará en nuevos principios, la ley y las buenas costumbres ${ }^{15}$. Entre sus obras está el establecimiento de tratados y alianzas con todos los pueblos vecinos como también la fundación del templo del dios Jano, una construcción bifronte; como la representación gráfica de la omnisciencia. También es el dios que vela por lo de dentro y lo de fuera, en el sentido que tienen los límites. La importancia del dios Jano es que se relaciona con la guerra o con la paz; se abre cuando hay guerra y se cierra cuando se obtiene la paz. Numa Pompilio cierra las puertas del templo a Jano, lo que significaba que Roma estaba en paz con sus vecinos ${ }^{16}$. Tito Livio nos entrega la noticia de que se cerró sólo dos veces después de Numa Pompilio: después de la Primera Guerra Púnica y en la época de Augusto; o sea, la Pax Augusta. Las fuentes muestran a Numa con el firme propósito de hacer menos rudo y violento a su pueblo, alejándolo del hábito del uso cotidiano de las armas ${ }^{17}$. Estos datos los podemos corroborar en el De Republica de Cicerón (1924), donde se confirman las acciones llevadas a cabo por Numa, el que, "al ver a los romanos enardecidos en los ejercicios bélicos instituidos por Rómulo, pensó que convenía apartarlos un poco de esa manera de vivir", quedando Numa como un modelo mítico de vida civilizada $^{18}$.

5 Tito Livio (1994-1997, 1, 19, 2).

${ }^{16}$ Tito Livio (1994-1997, 1, 19, 4): “Lo Cerró Numa una vez llevada a cabo la unión con los pueblos vecinos con tratados de alianza; al quedar libres de preocupación por el peligro exterior, para que la tranquilidad no relajase los ánimos que el miedo al enemigo y la disciplina militar habían refrenado, pensó que, antes que nada, debía infundirles el temor a los dioses, elemento de la mayor eficacia para una masa ignorante y en bruto por entonces".

17 Tito Livio (1994-1997, 1, 19, 2): “Comprendiendo que en un clima de guerra no podían aclimatarse a estas bases, porque la práctica militar vuelve más inciviles los ánimos, pensó que debía tornar rudo a su pueblo deshabituándolo de las armas".

${ }^{18}$ Cicerón $(1924,2,13$ (25)). 


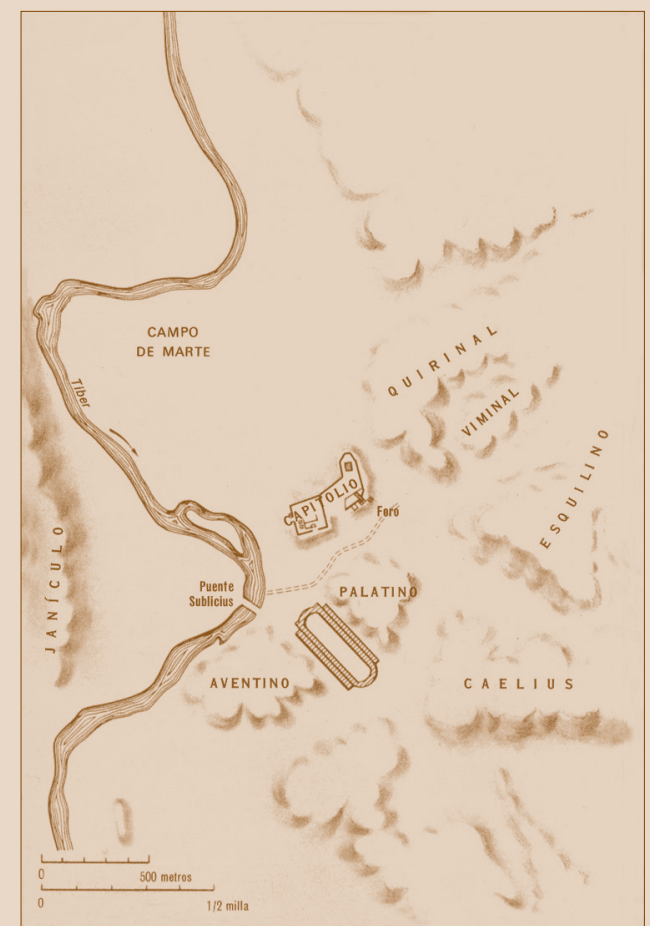

Las siete colinas de Roma.

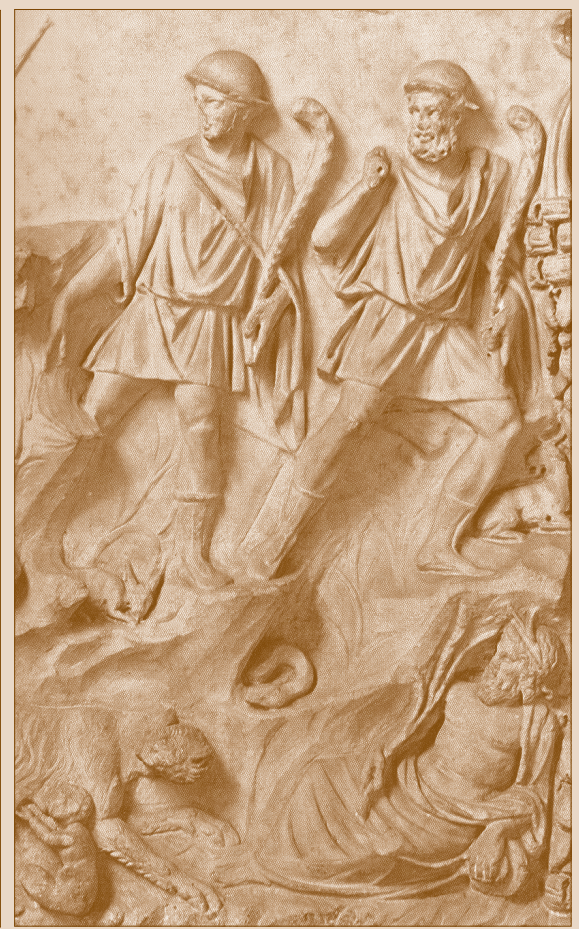

Ostia. Bajorrelieve de un altar romano que representa los orígenes míticos de Roma, fundada por Rómulo el 753 a.C. sobre la colina del Palatino. Roma. Museo Nacional Romano.

Estas medidas difundirán la imagen del rey en el Lacio y sus alrededores, las que inspirarán prácticamente todo su reinado, porque, después de las alianzas contraídas con sus vecinos, no hubo aparentemente ni guerras ni contactos diplomáticos de los que se le pueda hacer responsable. Numa es además el único rey sobre el cual las fuentes no nos entregan ninguna información sobre la recepción de alguna embajada extranjera. Sin embargo, habría que preguntarse si estos tratados lograron estabilizar las relaciones de poder en el Lacio.

La ausencia de relaciones diplomáticas no garantiza, en primer lugar, que los conflictos hayan desaparecido, sobre todo en áreas donde las tensiones eran permanentes. Hay que considerar además que la falta de iniciativa de Numa podría haber sido la consecuencia de una situación que este heredó desde la época de Rómulo, en la que el poder y la fuerza que el primer 
rey de Roma le entregó a la nueva ciudad le permitió asegurar la paz, a lo menos por los próximos cuarenta años ${ }^{19}$.

La alternancia entre un reino belicoso y un reino pacífico es posible gracias a las victorias de Rómulo, que permiten fortalecer el poder y la presencia de Roma en la región. Cicerón confirma que el territorio conquistado por Rómulo durante sus campañas va a ser distribuido por Numa entre los ciudadanos para que fuese cultivado por ellos, con el fin de procurarse los alimentos sin necesidad de saquear y obtener un botín, de modo que ellos experimentarán las bondades de la paz, de la justicia y de la lealtad. Si bien es cierto que su mayor preocupación fue la defensa de la paz ${ }^{20}$, da la impresión que Numa nunca descartó nuevas guerras, o que hubiera otros reyes belicosos como Rómulo. Numa aparece entonces como un monarca que intuye el futuro que lo sucederá, es decir, la fugacidad de la paz y de la guerra.

La extraordinaria importancia que Numa le dio a la religión y a la organización de esta hace que Roma frente a sus vecinos aparezca como una ciudad entregada totalmente al culto de los dioses, realidad posiblemente diversa a la del período anterior, por lo que atacarla es un verdadero sacrilegio, asunto que le garantizará al menos por un tiempo un periodo de cierta tranquilidad ${ }^{21}$. La imagen que proyecta Numa es, al parecer, muy potente; su piedad e innovaciones religiosas lo convierten en un personaje respetado por todos, dentro y fuera de Roma, siendo un monarca que renuncia al uso de la fuerza, que se sostiene en dos funciones antagónicas pero complementarias: por una parte la guerra, que está en la tradición originaria de Roma, y, por otra, la paz, que se apoya en el derecho y en la religión. Tito Livio afirma que estos dos reyes consecutivos engrandecieron Roma por caminos diferentes: uno a través de la guerra y el otro con la paz. Roma poseía, además de la fuerza, el derecho; un feliz equilibrio entre las instituciones de la guerra y las instituciones de la paz. Rómulo reinó treinta y siete años, Numa cuarenta y tres. Roma, además de poderosa, estaba equilibrada en sus instituciones militares y civiles ${ }^{22}$. Estos caminos serán, a lo largo de la historia republicana de Roma, los fundamentos de la expansión; la guerra y la paz contribuirán al poder de Roma. Estamos indudablemente ante una diplomacia aún incipiente, un tanto básica, pero, incluso así, esta al parecer juega un papel, por menor que este haya sido.

\footnotetext{
19 Tito Livio (1994-1997, 1, 15, 7).

${ }^{20}$ Tito Livio (1994-1997, 121,5$)$.

${ }^{21}$ Tito Livio (1994-1997, 1, 21, 2).

${ }^{22}$ Tito Livio (1994-1997, 1, 21, 6).
} 
Esta batalla por fin quebrantó el poderío de los samnitas de tal forma que éstos en todas sus asambleas andaban murmurando que, realmente, no tenía nada de extraño que nada les saliera bien en una guerra impía: emprendida en contra de un tratado, teniendo a los dioses más que a los hombres merecidamente en contra; había que pagar un alto precio en expiación por aquella guerra; sólo importaba si en los sacrificios derramaban la sangre culpable de unos pocos o la inocente de todos, y algunos se atrevían ya a citar por su nombre a los promotores de la guerra. Se podía oír sobre todo entre el clamor unánime el nombre de Brútulo Papio quien era un hombre noble y poderoso, responsable de la ruptura de la reciente tregua. Forzados los pretores a someterlo a debate, decretaron que Brútulo Papio les fuese entregado a los romanos y que juntamente con él se enviasen a Roma todo el botín de procedencia romana y sus prisioneros, y que fuesen devueltas, de acuerdo con el derecho humano y divino, todas las cosas que a tenor del tratado habían sido reclamadas a través de los feciales. Fueron enviados a Roma, tal como se habían acordado, los feciales y el cuerpo sin vida de Brútulo; éste, con su muerte voluntaria, se sustrajo a la infamia y al suplicio. Se acordó entregar también sus bienes juntamente con su cuerpo. Sin embargo, de todo aquel conjunto solamente fueron aceptados los prisioneros y lo que se identificó entre el botín: la entrega del resto no tuvo efecto.

Que haya operado solamente en una sola oportunidad, me parece un dato un tanto mezquino, por lo que me obliga a recordar y acudir a la existencia de toda una tradición acumulada en los siglos anteriores de la que quedan algunos residuos, en cuanto son elementos históricos constatables. Hay un extenso margen de elementos imponderables, inefables, que son igualmente parte de la dinámica histórica y que contribuyen por igual, y en algunos casos de manera preponderante, a lo que es la creación histórica. Al revisar los orígenes de las relaciones exteriores de Roma, no se debe ignorar lo que ha significado para toda la Historia posterior el pensamiento inefable que ha estado en los orígenes, que ha seguido estando después, y que, de algún modo, aún está presente en nuestra Historia.

Pero existen también otros aspectos que hay que tener presente; el eminente historiador Emilio Gabba piensa que en la figura y personalidad de Numa Pompilio confluyen en momentos diversos y sucesivos, no fácilmente determinables, una tradición romana y una interpretación griega. La primera está centrada principalmente en el origen sabino del rey, una realidad que de por sí permite ver la proyección de la costumbre romana de integración del extranjero; y la segunda, el rol de sus tradiciones familiares. El pitagorismo de Numa fue aceptado en Roma con la misma finalidad políticoideológica con la cual se había desarrollado: Roma entraba con su rey en el

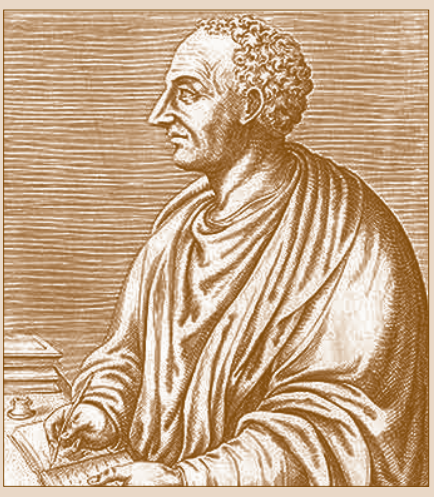

Tito Livio 


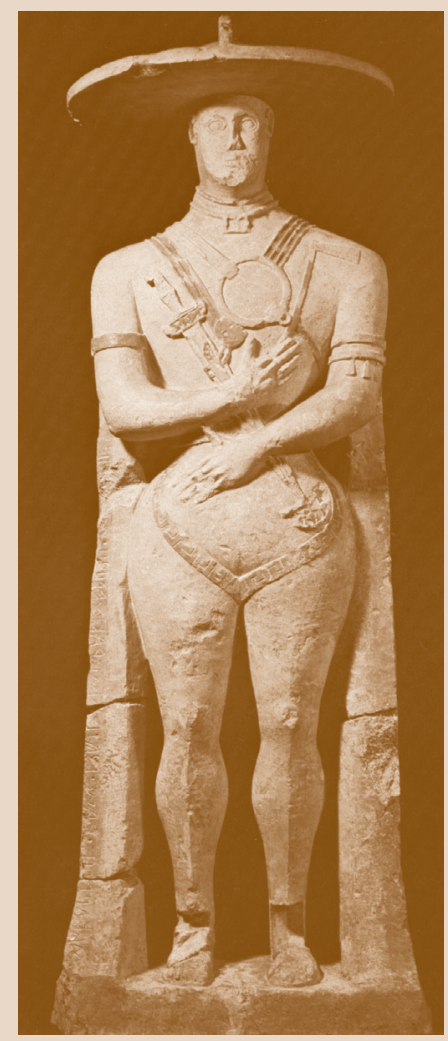

Estatua funeraria de un guerrero itálico proveniente de la necrópolis de Capestrano. Siglo VI a.C. Chieti, Museo Arqueológico. discipulado pitagórico común a otros pueblos itálicos, lo que le daba una suerte de legitimidad cultural y política, en momentos en que Roma aún no había logrado una hegemonía en Italia, y en el que recién se habían iniciado las hostilidades con los samnitas y continuaba el encuentro con el mundo etrusco. Es probable que el pitagorismo ingresara en el patrimonio cultural de una parte de la clase dirigente romana. No se puede dejar de lado que la personalidad del rey Numa, sabio, pitagórico y legislador pacífico, haya sido propuesta y aceptada, con el fin de superar la indudable dificultad ligada al mito del fundador de la ciudad. A pesar del mito de un Rómulo violento, jefe de bandidos y fratricida antes de convertirse en un legislador se las ingenia para superar los aspectos más negativos e imponerse rápidamente en la opinión pública. El rey Numa es el representante ideal de una política de paz, de sedentarismo agrario y de estabilidad en las fronteras.

Rómulo es, en cierto modo, la antesala de lo que vendrá con Tulio Hostilio, un rey guerrero y diplomático; las ambigüedades del reino de Anco Marcio; el crecimiento de las actividades diplomáticas durante los Tarquinio; la particular diplomacia de Servio Tulio y la dinámica diplomacia de Tarquinio el Soberbio.

Tulio Hostilio es un rey de contrastes: guerrero y diplomático. Tito Livio lo considera "más belicoso que Rómulo"27. La primera parte de su reinado se refiere al conflicto con Alba Longa (Pasqualini, 1996), en el cual hay situaciones bastante particulares. Por ejemplo, se efectúan seis contactos entre Roma y Alba Longa, los que son un caso excepcional durante la monarquía. Esto se debería, según algunos historiadores (Grandazzi,1986, p. 47-90), a que Alba Longa nunca fue una ciudad propiamente tal, sino que una zona densamente poblada en la cual vivían pueblos latinos y había un santuario federal. Esta realidad hace necesario ampliar los interlocutores. En la atmósfera del conflicto con Alba aparece la primera acción diplomática múltiple, con dos contactos sucesivos. El rey de Alba envió un legado antes de reunirse personalmente con Tulio ${ }^{28}$, pero curiosamente este doble acto se reemplaza por el combate entre los Horacios y los Curiacios, como si el enfrentamiento entre dos ciudades, tanto diplomático como militar, no podía realizarse ni directamente ni colectivamente. Sin embargo, este combate simbólico permite dos puntos de vista, el religioso y el diplomático, ya que fue acordado un foedus antes del famoso combate entre romanos y albanos. Este carácter excepcional de las relaciones de Roma con Alba

\footnotetext{
${ }_{27}$ Tito Livio (1994-1997, 1, 22, 2).

${ }^{28}$ Tito Livio (1994-1997, 1, 23).
} 
Longa queda ratificado porque es la primera ciudad en desaparecer del escenario diplomático. Desde el reino de Tulio las acciones de la diplomacia real buscan ampliarse y reforzar la integración de Roma a la Liga Latina, al interior de la cual las relaciones entre las ciudades deberán obedecer a reglas aplicables a todos sus miembros.

Para el reinado de Anco Marcio disponemos solamente del dato de cuatro acciones diplomáticas, lo que significaría una ostensible disminución de esta actividad; no obstante, parece ser que las iniciativas del rey nos permiten ver una política exterior bastante más agresiva que lo que aparenta. Esto se refuerza con la descripción que hace Tito Livio, quien describe a Anco "de un talante intermedio, que recordaba tanto a Numa como a Rómulo, $y$, aparte de estar convencido de que el reinado de su abuelo había tenido una exigencia mayor de paz por tratarse de un pueblo joven e indómito, lo estaba también de que a Numa le había sobrevenido la paz sin problemas, pero que él no la tendría fácilmente; se ponía a prueba su paciencia y, tentada, se la menospreciaba: eran tiempos más propios de un rey Tulo que de un Numa"29. Anco refuerza las creaciones religiosas de Numa mediante el desarrollo de los rituales de la rerum repetitio o solicitud de restitución o reparación. Es prudente entonces considerar que probablemente Anco basa sus normas de conducta en Numa como en Tulio. En el caso del asalto de la ciudad latina de Politorio, deportó a toda la población trasladándola a Roma, además de reforzar la presencia romana en dirección al mar, zona en la que al parecer se ubicaba esta ciudad. No nos olvidemos que, aun cuando hoy el tema está en discusión, se le atribuye a Anco Marcio la fundación de Ostia. Claudine Aulliard piensa que la ausencia de intercambios diplomáticos entre los que se presentan como conquistadores y los representantes de los territorios conquistados refuerza la improbabilidad de una conquista solamente romana (Aulliard, 2006, p. 69), hecho que nos permitiría suponer que detrás de estas operaciones estaba la potente participación etrusca. Da la impresión de que después de sus dos primeros contactos con los latinos pierde la iniciativa, y son los sabinos junto a los de Velitrae quienes entran en contacto con él. Martin (1982-1984, p. 256) cree en una colaboración impuesta o voluntaria entre Anco Marcio y las fuerzas etruscas. Se basa en el análisis de la actividad diplomática del último rey latino: después de su victoria sobre los latinos, el monarca ya no estaba en condiciones de tomar ninguna medida ni firmar acuerdos con sus vecinos o enemigos.

${ }^{29}$ Tito Livio (1994-1997, 1, 32, 3). 


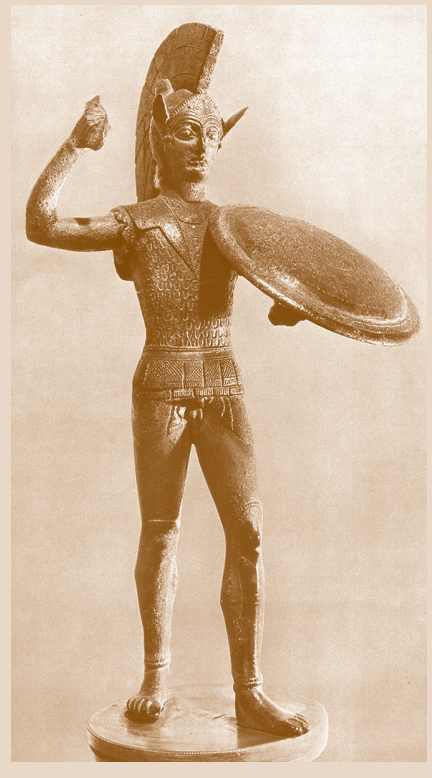

Arte Etrusco, siglo V a.C. Guerrero protector. El tema de los guerreros es común en los pequeños bronces etrusco-itálicos. Florencia, Museo Arqueológico.
La llegada de los tarquinios a Roma no constituye una ruptura en la historia de la monarquía, lo más probable es que haya sido la consecuencia de un acto individual más que el de una conquista (De Cazanove, 1988, pp. 615-648). Esto, porque la ciudad mantiene su identidad y sus características de ciudad latina. Las relaciones con los pueblos de Italia central se multiplicaron más allá del Lacio, especialmente con los hérnicos y con los ecuos, iniciándose una importante evolución en el desarrollo de la diplomacia, lo que queda en evidencia al realizarse los primeros contactos oficiales con representantes del mundo griego, primero los foceos y más adelante con Delfos. Esta relación, como sabemos, se fortalecerá con la concreción de un foedus entre los masaliotas y Roma, que los mantendrá unidos hasta finales de la República. Las relaciones entre estas dos ciudades son francamente sorprendentes y excepcionales, y se convertirán en las de más larga duración en toda la historia diplomática romana entre la fundación y el Imperio (Buono-Core, 1991, pp. 21-34). Sin lugar a dudas que los etruscos, abiertos al mundo griego, favorecen los contactos cada vez más amplios y novedosos que Roma logra.

Tarquinio Prisco, el primer rey etrusco, mantiene una intensa actividad diplomática con trece contactos de ese tipo. Una característica de este rey es que solo rara vez es el que inicia los intercambios diplomáticos. En efecto, solo dos de las trece misiones registradas en las fuentes habrían sido enviados por orden del monarca, el resto fue la consecuencia de la iniciativa de sus interlocutores latinos, sabinos o etruscos.

Servio Tulio fue el menos activo en materia de relaciones diplomáticas. Solo hay registro de tres de ellas. Esto no quiere decir que no haya tenido interés en mejorar sus relaciones con los pueblos vecinos. Por ejemplo, la construcción del templo en honor a Diana en Roma, obra conjunta de romanos y latinos, es un reconocimiento al liderazgo romano. Las guerras con Veyes y con los etruscos son precedidas de acciones diplomáticas, conflictos que refuerzan la teoría de que los acuerdos diplomáticos los contraen los reyes, los que, al desaparecer, estos pierden de alguna manera su vigencia, lo que obliga al rey siguiente a restablecerlos o enfrentar un conflicto. Servio prefiere la negociación antes de recurrir a las armas, hecho que queda corroborado al aparecer por primera vez el concepto de hospitium o derecho a la hospitalidad.

Las evidencias nos permiten ver que Tarquinio el Soberbio mantuvo una activa política exterior. Tito Livio afirma que trató de ganarse sobre todo al pueblo latino, para estar más seguro entre sus conciudadanos gra- 
cias al apoyo extranjero ${ }^{30}$. Privilegia las relaciones con los latinos y se refuerzan las relaciones de hospitium por los lazos de parentela. La alianza con los latinos le permitió contar con el poder militar necesario para hacer la guerra principalmente a los sabinos ${ }^{31}$, hecho que refleja la vocación expansionista de Tarquinio. En este contexto, con una atmósfera de polémicas y de propaganda antietrusca, la actividad diplomática de la cual es responsable permite ver a un rey determinado y conquistador en un territorio geográficamente más amplio que el que controlaron sus antecesores. Entre las guerras de Tarquinio, una sola de ellas fue precedida por una solicitud de reparación, el ataque contra Suesa, la ciudad más rica de los volscos, que será atacada, sitiada, derrotada y saqueada, con sus habitantes asesinados y esclavizados. Las otras guerras contra los sabinos, gabinos y Ardea no fueron declaradas. Aun así vemos que, en el caso de la guerra contra Gabios, esta finaliza con la promulgación de un foedus, conocido como foedus Gabinum, que habría servido de modelo algunos años después, el 493 a.C., para el foedus Cassianum $^{32}$. Diez de las acciones diplomáticas registradas por las fuentes son por iniciativa romana, lo que nos muestra un monarca que privilegiará el camino de la diplomacia para solucionar las controversias. Tarquinio parece preocuparse de otros problemas, como el de insertar a Roma en un horizonte más vasto del Mediterráneo. Una buena prueba de esto son las estrechas relaciones existentes entre Roma y Cartago, tema que ha sido discutido ampliamente por la historiografía de los últimos decenios.

A modo de algunas consideraciones conclusivas, se pueden detectar las características y el origen de las primeras formas de relaciones exteriores en Roma, de las que Rómulo es el principal responsable, a pesar de su aparente interés solo por las acciones militares. El derecho romano es un derecho ritualizado a través de fórmulas jurídicas, realidad ante la cual el papel de Numa va a ser definitivo en el respeto a los acuerdos y compromisos que Roma asumirá a lo largo de su historia, transformándose en el creador de una diplomacia protegida por los dioses. Estos dos reyes tienen, entonces, una responsabilidad determinante en la construcción de esa diplomacia como en la del mañana romano.

La relativa pobreza de la actividad diplomática de tres de los reyes Numa, Anco y Servio, y la gran actividad de los cuatro otros reyes, no tie-

\footnotetext{
30 Tito Livio (1994-1997, I, 49, 8).

${ }^{31}$ Dionisio De Halicarnaso (1984-1988, 4, 45).

${ }^{32}$ Dionisio de Halicarnaso (1984-1988, 4, 58, 3-4).
} 
ne el mismo significado, ni simbólica ni históricamente. En la tradición analística, cada rey es una imagen dominante que encuentra un eco en la práctica diplomática. Rómulo, el fundador, crea las primeras formas en las relaciones exteriores de Roma; Tulio, el agresivo, enriquece la diplomacia con funciones adicionales, con el fin de garantizar religiosa y legalmente los abundantes enfrentamientos que afectaban a la ciudad. Los reyes etruscos quedan marcados por las actividades diplomáticas de Roma, más allá de la monarquía, por sus innovaciones, por ejemplo la deditio ${ }^{33}$, y la amplia cobertura que logran en Italia y en el Mediterráneo. Numa y Servio tienen ideas relativamente claras, uno se centra en la organización religiosa y jurídica y el otro en la organización política y militar. En cierto modo, la escasa actividad diplomática de ambos habría que explicársela porque le dieron prioridad a las acciones de política interna. Sus innovaciones, la aplicación de una diplomacia diversa y abierta a los pueblos vecinos y también a los más lejanos, los reyes, especialmente los tarquinios, dan inicio a una diplomacia romana genuina y creíble que se proyectará en los siglos posteriores.

\section{REFERENCIAS}

Alföldi, A. (1965). Early Rome and the Latins. Ann Arbor: Jerome Lectures. Seventh Series.

Aulliard, C. (2006). La diplomatie romaine. Rennes: Presses universitaires.

Buono-Core, R. (1991). “Roma, Marsella y el Mediterráneo occidental”. Semanas de Estudios Romanos, VI, 21-34.

Carandini, A. (1997). La nascita di Roma. Dèi, Lari, eroi e uomini all'alba di una civiltà. Turín: Einaudi, Biblioteca di cultura storica, 219.

\footnotetext{
${ }^{33}$ Cuando una ciudad era obligada a la capitulación, Roma decidía si esta sería arrasada (deditio in dictionem), siendo sus dirigentes generalmente ejecutados y el resto de sus habitantes vendidos como esclavos o bien convertida en una ciudad dediticia (deditio in fidem), lo que significaba que Roma se apropiaba de los bienes y las personas de la ciudad y posteriormente se restituían con la condición de dejar establecido el stipendium, un tributo fijo regulado por el gobernador romano, así como levas de personas para tropas auxiliares de los ejércitos romanos, víveres a precio estipulado de antemano (lo que facilitaba abusos que generaban nuevas revueltas) y servicios. Además la ciudad debía permitir en su recinto el establecimiento de una guarnición romana. En cuanto a la administración, Roma generalmente respetaba las instituciones y el modo de gobierno interno, puesto que el derecho de política exterior quedaba sometido totalmente al poder de la República. La ciudad dediticia quedaba privada de todo derecho jurídico para sus habitantes, lo que la colocaba en el último escalón de la ordenación municipal romana, que estaba configurada con las colonias romanas en lo más alto del estatus jurídico, a las que seguían los municipios romanos y después las ciudades peregrinas o extranjeras. En el caso de quedar arrasada como castigo ejemplar, la ciudad dediticia se convertía en ager público de Roma.
} 
Cicerón (1924), De Republica. En: Obras completas, t. VI. Traducción de D. Francisco Navarro y Calvo. Madrid: Librería de los Sucesores de Hernando.

Cornell, T. (1980). "Alcune riflessioni sulla formazione della tradizione storiografica su Roma arcaica”, en Roma arcaica e le resentí scoperte archeologique. Giornate di studio in onore di U. Coli-Firenze, 29-30 Maggio 1979. Milano.

De Cazanove, O. (1988). "La chronologie des Bacchiades et celle des roi étrusques de Rome". MEFRA, 100, 615-648.

Dionisio de Halicarnaso (1984-1988). Historia antigua de Roma. Tad. E. Jiménez, E. Sánchez, A. Alonso y C. Seco. 4 vols. Madrid: Gredos.

Gabba, E. (1967). "Considerazione sulla tradizione letteraria sulle origini della repubblica", en Les origines de la République Romaine, Genève: Entretiens Hardt, XIII, pp. 137 ss.

Gabba, E. (2001). "Ancora sulle origini di Roma". Athenaeum, 89, 589-591.

Grandazzi, A. (1986). "La localisation d'Albe”. MEFRA, 98, 47-90.

Grandazzi, A. (1991). La fondation de Rome. Réflexion sur l’histoire. París: Les Belles Lettres.

Letta, C. (1988). “La Tradizione Storiografica sull'età Regia: Origine e Valore en Alle Origini di Roma”, en Atti del Colloquio tenuto a Pisa il 18 e 19 settembre 1987. Pisa: Giardini Editori e Stampatori.

Liou-Gille, B. (1997). "Les rois de Rome et la ligue latine: définitions et interprétations". Latomus, 56, 729-764.

Livio, T. (1994-1997). Historia de Roma desde su fundación. Madrid: Gredos.

Martin, P. M. (1982-1984). L'idée de royauté à Rome. I. De la Rome royale au consensus républicain; II. Haine de la royauté et séductions monarchiques (du IVé siècle av. J.-C. au principat augustéen), 2. vols. Clermont-Ferrand: Miroir des civilisations antiques, 1.

Pasqualini, A. (Ed.) (1996). Alba Longa. Mito. Storia. Archeologia. Atti dell'Incontro di Studi di Roma Albano Laziale 27-29 gennaio 1994. Roma: Studi pubblicati dall'Istituto Italiano per la Storia antica, 60.

Plutarco (1985a). “Numa”, en Vidas paralelas (pp. 339-397), t. I. Introducción general, traducción y notas por Aurelio Pérez Jiménez. Madrid: Gredos.

Plutarco (1985b). "Rómulo”, en Vidas paralelas (pp. 205-272), t. I. Introducción general, traducción y notas por Aurelio Pérez Jiménez. Madrid: Gredos.

Poucet, J. (1985). Les origines de Rome. Tradition et Histoire. Bruselas: Publications des Facultés universitaires Saint-Louis, 38. 